\title{
Sustainable Islamic Development Recognising the Primacy of Trust, Iman and Institutions
}

\author{
Nazim Zaman \& Shafiullah Jan
}

\begin{abstract}
Modern socio-economic writings on trust have contributed much to its understanding as an important element in studying human behaviour in society. Recent literature on development studies has highlighted social capital as a term, which incorporates ideas of value and benefit embedded in social networking, while others have demonstrated trust to be very significant when studying social capital. This study will identify some fundamental assumptions of modernity which prevent the better understanding of trust as a human entity and then propose that Islamic ontology, not confined by any such assumptions, provides a greater understanding of the role of trust in society through the concept of iman (cognitive faith).
\end{abstract}

Islamic economics in its modern form had set out to achieve the development of the axioms of Islamic thought in society by proposing that values derived from Islamic ontology such as wealth distribution and social justice could be amalgamated with conventional economic theory to make it morally more acceptable. However, these fundamental building blocks of Islamic society remain absent, whilst Shari'ah compliant tools and methods continue to grow in the market, which has led to criticism from some quarters in terms of the social failure of Islamic finance. This paper will attempt to understand possible reasons for this failure by addressing fundamental methodological issues.

Analysing, through study of authentic Islamic ontological and epistemological foundations, the concept and functions of the essence of iman, with its actualisation and its relation to the human developmental paradigm of Islam, a dual phase model of Islamic development methodology is proposed by this study. This model seeks to elaborate the multiple functions of iman at the individual, societal and institutional levels and then compare these with those of trust and social capital in modern thought.

Hence the dynamic and interdependent nature of the Islamic development methodology will be highlighted and the function of trust will be located within the Islam-Iman-Ihsan paradigm. This sequential approach indicates the Lecturer Durham Centre for Islamic Economics and Finance School of Government and International Affairs Durham University, UK, Email: n.a.zaman@durham.ac.uk Tel: +44 (0)7817783385 
primacy of iman as both the foundation and the continuing core of all Islamic development upon which frameworks and institutions are to be built. As such iman is shown to provide the bonding fabric, or trust, which subsequently organically spawns Islamic institutions and those institutions must be such that they, in turn, bolster the level of iman in the society. Hence using this model, the reasons for failure can be located at both the foundational level and the institutional level in terms of failures of iman or trust.

\section{Introduction}

Development is generally taken to mean 'betterment' or 'progress' and in terms of society it is taken to mean the 'betterment of all'. However it soon becomes obvious that such definitions carry inbuilt subjectivity in that words such as betterment and progress assume an underlying understanding of what is good and what is desired. As such development is not a universal concept but has come to mean differing things to different people. Literature on economic development is dominated by conventional capitalist thought and hence tends to suggest that the only route to development is to imitate the west as the underlying notion is that what the west has achieved is the pinnacle of human development.

Recently in post-structural and post-developmentalist literature the above assumption has been challenged and it has been suggested that indigenous, organic and even traditional models of development are not only valid but actually better serve humanity across the globe. In this vain there have been attempts to revisit such models and to discover new ones. Islam has become the focus of attention in many circles as it had demonstrated long-lived development based on principles at great variance with the later capitalist model. This paper is part of an attempt to discover the underlying ontological principles upon which Islamic development is based and upon which any society may develop according to Islamic values. One important element in any society's development is the trust fabric which progresses mankind from individuals to social players. This paper will attempt to analyse the nature and dynamics of the fabric which binds any Islamic society.

\section{The meaning of trust}

Trust has become a crucial part of studies from within varied fields of economic and social science. These include transaction cost economics (Williamson, 1985), economic sociology (Granovetter \& Swedberg, 1992) and political science (Putnam, Leonardi, \& Nanetti, 1993). The debate is a wide ranging one and crosses many disciplinary boundaries. This has led to a some- 
what confused and confusing picture of what exactly trust is and how it affects development in any way. Each discipline within the social sciences sees trust through its own particular glasses and so we have many usages and definitions bounding about, none of which can be particularly definitive. For the purpose of this study two of the broad approaches to trust will be considered. These are the economic science approach, sometimes referred to as individualistic rationality or calculative theories of trust and the sociological approach which seeks to address trust in terms of common social values or norms and sees it as adding to what Putnam labelled "social capital" (Putnam et al., 1993). Common to both is the idea that trust is a phenomenon that can be identified in society by the results it produces in terms of enabling, facilitating and affecting exchange.

The literature on trust extends to the realms of philosophy (Williams, 1988), political science (Dunn, 1988); and social anthropology (Hart, 1988), but its conceptualisation has commanded particular attention from economists and sociologists. Trust has arisen as a key issue in transaction cost economics (Williamson, 1993), game theory (Dasgupta, 1988), sociology (Luhmann, 1979), and economic sociology (Granovetter, 1985). Yet despite the plethora of material emerging on the subject, in the words of Gambetta (1988, p. ix), trust remains an "elusive notion". He argues that beyond acknowledgement of its importance, analysis of trust has been undermined by its pervasiveness in the face of the increasingly specialised social sciences:

"[T]his very pervasiveness [of trust] seems to have generated less analysis than paralysis: in the social sciences the importance of trust is often acknowledged but seldom examined, and scholars tend to mention it in passing, to allude to it as a fundamental ingredient or lubricant, an unavoidable dimension of social interaction, only to move on to less intractable matters." (ibid.)

In recent years, however, interdisciplinary discourse has grown and trust has emerged as an evocative theme upon which interest across the social sciences has converged (Swedberg, 1987). Shapiro (1987) notes that the conceptualisation [of trust] has received considerable attention in recent years, resulting in a confusing potpourri of definitions applied to a host of units and levels of analysis'.

It seems as though the pervasiveness of trust which once deterred its analysis, has now led to a proliferation of definitions each used in a different con- 
text. As Sztompka (1995) rightly points out, trust is defined by some as a characteristic of a particular class of action, while others identify it as a precondition for any such action to take place. At the same time, some discuss trust with reference to governments and organisations, while others examine trust between individuals or people in particular roles.

Definitions of trust differ not only between disciplines, but also within disciplines. As Coleman (1988) argues, "Elements of these two intellectual traditions [economics and sociology] cannot be brought together in a pastiche. It is necessary to begin with a conceptually coherent framework from one and introduce elements of the other without destroying that coherence".

Gambetta (1988, p. 219) provides a simple definition that can be refined according to the purpose of investigation; "trusting a person means believing that when offered the chance, he or she is not likely to behave in a way that is damaging to us". The precise aspects of definition one takes will vary depending on which manifestation of trust one wishes to analyse, however the main thrust of existing economic studies is towards studying the effects of trust on relationships between economic agents and how or if these effects can be measured, predicted or manipulated. Thus the focus of the following sections will be on the relevance or otherwise of trust to socio-economic development.

\section{Trust and social capital}

The work of sociologist Niklas Luhmann (1979) gives insight into trust as a social phenomenon. Like Williamson, he argues that calculativeness is antithetical to trust, however he reaches the opposite conclusion and suggests that trust is not a prediction, the correctness of which could be measured when the predicted event occurs and after some experience reduced to a probability value. He further states that these types of techniques which are significant within the framework of decision-making models, are functional equivalents of trust but not acts of trust in the true sense. As far as they extend, trust is unnecessary (Luhmann, 1979).

\section{Trust and social order in modern thought}

The evolutionary path of both economic thought and sociology seems to be converging towards greater eclecticism using amalgamations of rational selfinterest and moral values. In this way new institutional economics and development economics seem to be borrowing heavily from sociology and perhaps, it may be suggested, even merging into it.

Rather than isolating trust as either a cause of order or a consequence of it, a novel and comprehensive approach can be suggested. Trust is belief and action; cause and effect; condition and result. Rather than assuming trust is of 
different distinct types, trust can be taken to be the same essential phenomenon but one that constantly and consciously is adapted to fulfil distinct purposes in varied situations. From this perspective whether interpersonal or general, system or community, trust in these situations is essentially the same phenomenon but the functions and effects are varying and appropriate to each requirement. Applying this view to social order it can be stated that trust is each of the following.

a) The prerequisite of social order - in so far as individuals must trust others to some extent in order to constitute society.

b) A sustainer of true social order itself - as the absence of trust means the collapse of such order

c) The consequence of social order - because order results in institutions which further stabilise the order and so bolster trust

Considering each of the three situations given above in more detail, the roles, functions and results of trust in each one may be explored.

a) Trust at an individual level enables decisions and choices to be made efficiently and ultimately emanates from knowledge held about numerous material and moral realities. Individual trusting behaviour is a pre-requisite to any social co-operation and so to social order

b) Trust at a social level must be the very fabric of the society and give rise to institutions through actions of all members based upon commonly held beliefs and aiming at common goals and ends

c) Trust must be, by definition, the intended consequence of social order. The purpose of social order is the establishing of trust and it achieves this through the feedback effect of institutions on society

Among the implications of this three-stage model is the relationship of trust to ends or goals. At the individual level trust grows out of personal beliefs which in turn are the determinants of the person's view of ends or goals. Thus beliefs and convictions underpin ontology from which is formulated a conception of virtue and hence a sense of morality and values. Each individual's own belief of what constitutes a goal eventually leads that individual to work towards it and inevitably interact and co-operate with others. This holds whether the envisaged goal is pure self-interest, or pure altruism based on a faith in virtue, or anything in between the two extremes.

\section{Virtues, morality and modernity}

Any moral philosophy fundamentally presupposes a sociology as, by ne- 
cessity, every moral philosophy offers, either explicitly or implicitly, a conceptual analysis of the relationship of a person to his or her reasons, motives, intentions and actions and in doing so it generally presupposes that these concepts are embodied in the real social world. Thus it follows that we cannot fully understand the claims of any moral philosophy until we have outlined what its social embodiment would be. This was the view of moral philosophy held by Socrates and Aristotle and indeed also Hume and Adam Smith; but since Moore's Principia Ethica, and probably earlier, a narrow conception of moral philosophy has dominated and enabled moral philosophers to ignore this task. This narrow conception finds its roots in the theory of emotivism.

Emotivism is the belief that all moral judgements are purely expressions of attitudes, preferences or feelings. These are sharply contrasted with factual judgements which can be either true or false. Hence, it is claimed, as moral judgements cannot be shown to be true or false, no agreement can be reached in the moral sphere by any rational method. Moral argument, according to emotivists, is only used to forward our own feelings and attitudes and by doing so, produce the same in others. Without going into deeper philosophical discussions it is, nonetheless, important in this study to understand the social impact of emotivism.

The emotivist self becomes completely distinct from its social embodiments and also lacks any rational history of its own. If this emotivist self is compared to its historical predecessors a sense of loss can be envisaged. The emotivist self can be seen as having suffered a deprivation, a stripping away of qualities that were previously believed to belong to the self. The self thus becomes thought of as lacking any social identity, because the very kind of social identity that it once held is no longer available; the self is now without criterion, because the kind of telos it once employed to judge and act is no longer thought to be credible. In order to rediscover these criteria or telos which enabled the pre-emotivist self to claim social identity it is necessary to explore that social identity.

In many pre-modern, traditional societies the individual identifies himself or herself through his or her membership in a variety of social groups. Brother, sister, cousin and grandson, member of this family, that tribe, this village, or indeed creation. These characteristics do not belong to people accidentally, to be stripped away in order to discover 'the real self'. They are an integral part of peoples' substance, defining, at least in part and sometimes completely, their obligations and duties. However, to identify oneself as such a social person is not to occupy a static position but rather to find oneself 
located at a certain point on a journey with set goals; to move through life is to make progress, or to fail to make progress, toward a given end. A completed and fulfilled life is, thus, an achievement and death is the point at which someone can be judged happy or unhappy. Hence the ancient Greek proverb: 'Call no man happy until he is dead.'

However, at some point in the move towards modern 'development' the concept of a holistic life, which has purpose and aims towards some end and which uses the criteria of that end as judgement aids in rationally assessing the success or otherwise of efforts made, has been lost or abandoned. This has been seen not as a loss but has been hailed as the achievement of freedom from restrictions of social systems and the supposed superstitions of tradition. Thus the emotivist self has lost its traditional locus and social identity. This is far from development in any social sense.

The Enlightenment project that gave birth to emotivism, amongst other attempts to find a basis for morality using that rationality which by definition is silent on matters of morality, is where morality was detached from any sense of telos. The Jansenist Pascal, Hume, Kant, Diderot, Smith and Kierkegaard all rejected any teleological view of human nature, any view of man as having an essence which defines his true end.

The moral philosophers of the eighteenth-century were engaged in what was an inevitably unsuccessful project; because they certainly attempted to locate a rational basis for their moral beliefs in a particular understanding of human nature, while they had inherited a set of moral injunctions and a conception of human nature which had been specifically designed to be at odds with each other.

It is understood then, that if trust is to be examined as a phenomena related to virtues, morality, beliefs and higher end goals for society or humanity, it is not to be done within the so-called 'rationalist' framework of social science as laid out by the Enlightenment and post-Enlightenment thinkers, as this framework does not allow any moral judgement or act to exist as a social truth attainable by rational means. Instead such a reality is to be best understood in terms of a framework which is wholly based upon the concepts of rationally definable virtues and end goals common to all humanity. Such a framework would be one that existed in pre-modern thought generally and in religious thought specifically.

The framework provided by Islamic ontology is a holistic one which continues to this day to combine concepts of belief, morality, virtue and rational- 
ity in a way which was eliminated in Christianity by the likes of Calvinism. Hence it would follow that exploring Islamic thought for any illumination of the concepts of trust and virtue may well produce beneficial insights for the purpose of this study.

\section{Iman, ihsan and 'amal - An authentic Islamic framework of virtue, trust and its actualisation}

Before discussing any matter from an Islamic perspective it is necessary to present the underlying ontological principles from which it springs as these are more often than not distinctly at variance with what one may assume to be their equivalent in conventional western thought. It is an essential prerequisite to return to first principles in order to avoid taking on board any assumptions obtained from within that conventional modern framework which itself is a deliberate result of the Enlightenment project mentioned above which

aimed at removing all traces of morality or virtue based upon any notion of religion or revelation.

One of the earliest formulations is found in a famous hadith (a saying of the Prophet) called the "Hadith of Gabriel," in which the Prophet divides "the way of life" that is, the deen, into three basic dimensions. In naming these three dimensions, the Prophet employed terms that have played important roles in Islamic intellectual history:

- Islam (submission)

- iman (faith), and

- Ihsan (virtue)

In order to understand the deen of Islam as a reality possessing these three dimensions one must grasp some of the implications of these words in the Qur'an and the Sunnah.

\subsection{The first dimension - Islam}

Considering the first dimension we see that in the Qur'an, the word Islam, meaning 'submission', can be understood to have at least four senses, all of which are concerned with the relationship between Allah and His creatures.

In the broadest sense, Islam is used to convey the idea that every creature, by the fact of being Allah's handiwork, is controlled by Him.

To Him 'submits' everything in the heavens and the earth, willingly or unwillingly and unto Him they will be returned (Q3:83). 
In a narrower sense, Islam means voluntary submission to Allah's will by following His revealed messages. The Qur'an mentions the prophets among the 'Muslims' that is, those who have freely submitted to Allah.

Abraham was not a Jew, nor yet a Christian; but he was an upright man who had surrendered (to Allah), and he was not of the idolaters (Q3:67)

Similar verses use the word muslim for Yusuf (Q12:101), Nuh (Q10:72), Lut and his family (Q51:36), the apostles of 'Isa (Q5:111), and other pre-Islamic figures. Even Pharoah claims to be a muslim when he realizes that he is going to be drowned (Q10:90).

In a third and still narrower meaning, Islam designates the religion revealed to Muhammad through the Qur'an. The most obvious Qur'anic example of this usage is the verse revealed at the Prophet's farewell pilgrimage.

Today I have perfected your religion for you, and I have completed My blessing upon you, and I have approved Islam for you as a religion (part of Q5:3).

In the fourth and narrowest sense, Islam refers to the outward works of the religion as distinguished from an inner something that makes the religion genuine and sincere. One verse is especially significant, since it differentiates between Islam and iman, submission and faith.

The Bedouins say, "We have faith." Say [O Muhammad!]: "You do not have faith; rather, say, 'We have submitted;' for faith has not yet entered your hearts" (Q49:14).

In this fourth sense, Islam corresponds to one of the three dimensions of Islam, and hence its meaning needs to be clarified if we are to understand the meaning of Islam in the third sense.

The Hadith of Gabriel differentiates even more clearly than this Qur'anic verse between Islam in this fourth sense and iman. It is true that some Qur'anic verses and Hadiths use the two terms as synonyms, but this does not prevent the texts from drawing distinctions in other contexts. According to this Hadith, Islam consists of the 'five pillars or foundations': saying the double Shahadah (bearing witness that there is no ilah (god) but Allah and that Muhammad is His messenger), performing the ritual prayer, fasting during the month of Ramadan, paying zakah (the alms-tax), and performing the hajj if one has the means to do so.

\subsection{The second dimension - iman}

The second dimension of the deen is iman (faith). The Qur'an frequently 
employs the term and various semantically derived words, especially the plural of the active participle, mu'minoon (those who have iman, the faithful). Although translators normally render iman as "faith" or "belief," such translations leave out an important connotation, because the word derives from a root, amana, which means to be secure, safe, and tranquil. Hence, the literal sense of iman is to render secure, safe, calm, and free from fear. The implication is that, through iman in Allah, one becomes secure from error and rooted in the truth. iman has a cognitive dimension that is a step in the direction of certainty. For this reason this study will use the Arabic word 'iman' and the English phrase 'cognitive faith' or 'cognitive trust' when needed for explanation. In a number of verses the Qur'an provides a list of the objects of iman. For example,

But righteous is he who believeth in Allah and the last day and the angels and the Scripture and the prophets (Q2:177)

In the hadith of Jibreel, a formulaic expression is given to these objects by defining iman as "having iman in Allah, His angels, His scriptures, His messengers, the Last Day, and the measuring out of good and evil." Worthy of notice is the fact that the prophet repeats the word iman in the definition itself, which indicates that here, as opposed to certain other hadiths, the meaning of iman is not at issue, but rather the objects of iman. All the objects mentioned in the hadith are studied to various degrees in the Islamic sciences of Kalam, Fiqh and Tasawwuf.

\subsection{The third dimension - Ihsan}

The third dimension of the deen is ihsan (perfection or virtue). The Prophet employed the word ihsan, which is the most difficult of the three terms to translate. It is an active form from the root hasana., which means beautiful and good. Hence, the word ihsan means to accomplish what is beautiful and good, to do something well, to do something perfectly, to gain perfect and virtuous qualities. The standard by which the good, the beautiful, and the virtuous are judged cannot be an individual's opinion, because at issue here is what the religion teaches. In the hadith of Jibreel, the ihsan is defined as "serving [or worshiping] Allah as if you see Him, because if you do not see Him, He nonetheless sees you." In other words, this third dimension of Islam is concerned with depth, or the inner attitudes that accompany activity and thought. According to this definition ihsan implies that one must be aware of Allah's presence in everything one does which is to say that one must have a state of soul in conformity with works and iman.

From the above discussion it is possible to clarify the Islamic conceptualisation of iman as a form of cognitive trust which also entails a par- 
allel element which is actualised in actions. At the same time ihsan is the perfection and end which is the sole object of good actions. Hence ihsan is virtue, to borrow an Aristotelian term, and iman is the cognition, gained through inner and outer reflection, which identifies this virtue for the human being, and enables him to be safe and secure on the journey towards it.

This conception of iman, 'amal and ihsan is further supported by realising a Qur'anic linguistic technique. It is a feature of the Arabic language that word order in sentences is not fixed but can vary with differing results in degree rather than meaning. When applied to Qur'anic verses the mufassireen (exegists) have noted that this technique is widely employed. Words often precede others in order to express precedence in time, importance, emphasis or any combination of the three.

One of the most oft repeated phrases in the Qur'an is the following: 'those who have iman and do good acts'. This indicates, according to the linguistic inference, the precedence of iman over 'amal. Keeping in mind the earlier definition of iman as being inclusive of 'amal, what is implied then is that the cognitive aspect of iman is a prerequisite for good actions and hence is the first which needs to be established. In other words, the Qur'anic view of success is to first recognise the ultimate perfection, Allah, and then act in such a way as to move towards that perfection. Obviously any act cannot be deemed virtuous until one first is sure of what virtue is. This observation has important implications for trust and development in Islamic terms as will be discussed.

Hence iman has a component which realises the knowledge of the ultimate virtue and secondly another component which actualises this knowledge through actions so as to progress towards that ultimate virtue. These components can be labelled as the vertical, through which man knows Allah, and the horizontal, which entails virtuous acts that move one towards Allah. This categorisation of iman is a very useful one. Combining the above categorisation of vertical and horizontal iman with the previous observation that iman is best understood as cognitive trust, it becomes possible to elucidate an Islamic concept of trust in terms of iman, 'amal and ihsan.

Firstly the vertical qualities of iman are seen to be purely functions of the relationship of an individual with Allah. Traditionally referred to as qualities of the "heart", they form the essential foundation of Islamic life. Without this component all Islamic axioms are rendered insignificant and irrelevant to life and hence we can say that this vertical aspect of trust gives conceptual realisation to other axioms.

Recalling the earlier three-stage formulation of trust it is now possible to equate this vertical component of iman with the personal, individual based 
trust which emanates from the knowledge of realities, and which is a prerequisite to any social realisation of trusting behaviour.

The second category includes the horizontal aspects of iman which are only realised in relation to actions. These aspects directly affect human relationships in society and so impinge on the actualisation of Islamic axioms such as khilafah (vicegerence), ukhuwwah (brotherhood) and adalah (justice) etc.

This horizontal component correlates with the second stage of trust at a social level which is the very fabric of the society and gives rise to institutions through actions of all members based upon commonly held beliefs and aiming at common goals and ends. Hence it is possible to express the notion that the horizontal component of iman as an actualisation of the cognitive trust in Allah, in turn enables, and indeed encourages, the individual to demonstrate trust and trusting behaviour towards others in society. The degree to which this trust is realised in society will determine the degree to which the developmental axioms of Islam are realised in the institutions of that society.

\section{An integrated model of iman / trust}

If the above conceptualisation of iman as cognitive trust which can be used to explain the workings of an Islamic development model, is to be helpful at all in formulating an implementable Islamic development theory that can lead to practical policy formulation, it is important to determine the mechanisms which will enable iman to become actualised in society and in turn facilitate the establishment of supportive institutions, and also the dynamic relationship of such institutions to iman itself.

It is suggested here that vertical elements of iman enable individuals to actualise horizontal elements in society insofar as when there is an increase in individuals sharing cognitive realisation or belief so there is an increase in mutual trust amongst those individuals. This cooperation or mutual trust is motivated not by risk assessments or calculations, but by knowing that such action, if intended to enable one to get closer to the ultimate happiness, is beneficial regardless of material outcome. This is because iman is not blind faith but is rather a cognitive recognition of Allah as the ultimate good which is to be sought in life. This shared knowledge, or realisation, leads to a 'weave' of trust relationships developing which creates a 'fabric' of trust in society. Initially this trust may be low-level existing only between family members or those known to each other, however at some point a critical mass will be reached whereby this fabric of trust will be strong enough to support the institutionalised 
realisation of values and axioms. Importantly, it is suggested here that supportive institutions must therefore arise from the cognitive trust present in society if they are to be functional.

We have seen that vertical aspects of iman expand the pool of interpersonal trust and this in turn when it reaches a critical level spawns a society wide trust fabric which enables the establishing of institutions and the actualising of the axioms. However the institutions themselves, in turn, function to engender and support trust by embedding, throughout the society, values such as 'adl (justice), aman (security), huqooq (rights) and ukhuwwah (brotherhood). Hence there is a "feedback" effect that serves to further expand the pool of trust, the expansion of which enhances and supports the institutions. Hence those members of society who may not initially possess cognitively based iman would be able to benefit from the institutional support and hence may become inclined towards the values which spawned those institutions. In this way a society of Muslims and non-Muslims may function where both groups actively support the iman based institutions by willingly valuing the iman based trust fabric. The overall result is the upward dynamic of human development as defined in Islam. This feedback effect is the third stage of trust outlined earlier, whereby trust is an outcome, or product, of the institutions that it helped spawn initially.

The above discussion can be represented in diagrammatic form as follows.

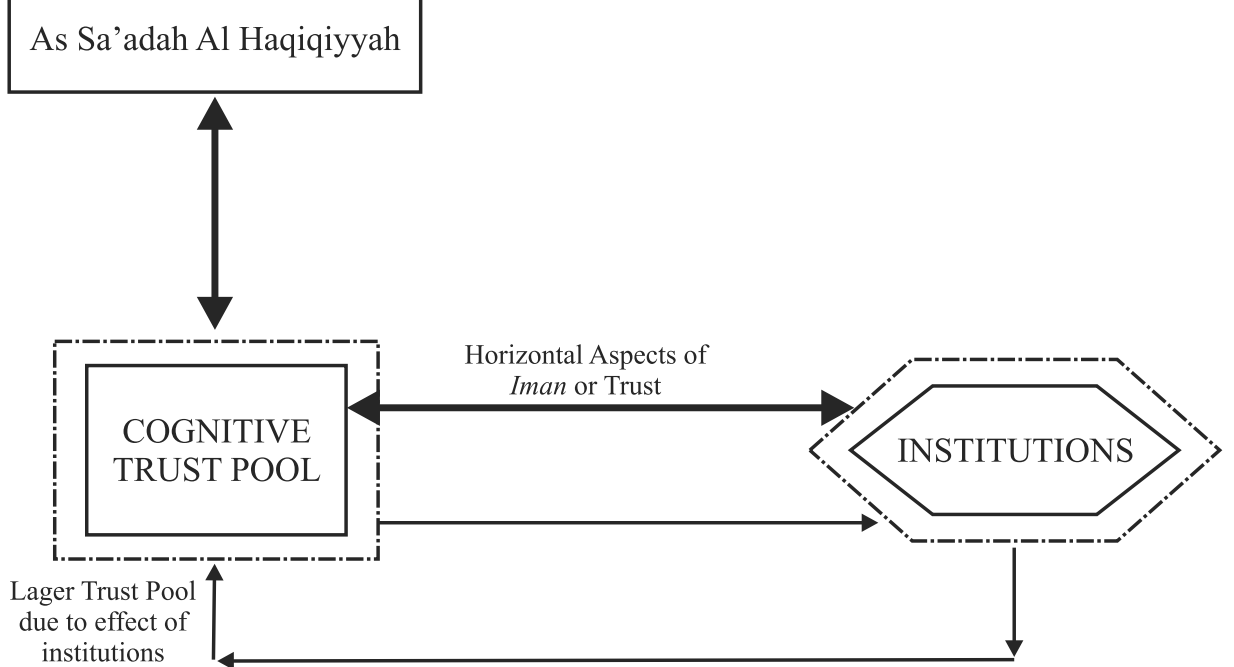




\section{Conclusion}

The positive correlation of trust and social order has been established conclusively in social, political and economic literature spanning several centuries. However engaging with the intricacies and mechanisms of its nature, functions and factors has proved to be a challenge and has resulted in it being assigned by most writers to the rather nebulous category of social capital á la Putnam et al.

Modernity and its conventional philosophy and analysis in socio-economic spheres precludes consideration of virtue and morality as anything other than a subjective construction of the individual mind, taking the perspective, as it is bound to do, of its alma mater the Enlightenment project of the eighteenth and nineteenth centuries. However this perspective also leads to the preclusion of several aspects of human behaviour exhibited in trusting relationships which in turn prohibits precisely that understanding of trust which can explain its function as social capital and bridge the seemingly great divide between individual and societal interaction. Hence by bringing the concept of ultimate virtue into view, trust can be seen to have motivations, functions and forms which better explain the 'social capital' role it most definitely fulfils.

Assuming the existence of a widely held concept of ultimate virtue, or sumum bonum, which the constituent elements of society proximate towards, through utilisation of embedded social resources, in order to develop, the function of trust can be identified and categorised at three separate, but dynamically intertwined and interdependent, levels. At the individual level it establishes the concept of virtue as the ultimate goal and enables the interactions of individuals on that basis. Furthermore, trust in common values then provides the fibre for weaving the institutional fabric designed to support and bolster society along developmental lines. Lastly, trust is itself an outcome and product of those social institutions and hence feeds back to expand the initial trust pool which initiates the developmental process.

Islamic ontological and epistemological sources provide a virtue-centric socio-economic framework pivoting around and essentially stemming from the conceptualisations of Allah and accountability. The primary element in this framework is quite obviously the cognitive faith in these conceptualisations known as iman. It forms the fundamental basis of the deen of Islam and the structural spine of all of its theory and guidance including the socio-economic models of development. The essence of iman begins in the individual sphere and its actualisation is to be seen at societal and institutional levels. In this way the concept of iman in Qur'anic discourse has significant and revealing 
parallels with the concept of trust as earlier expounded, and clearly fulfils roles and functions of individual trust and also forms the most critical component of social capital.

The textual, contextual and linguistic analysis of Qur'anic revelation under the categorisation of Makkan and Madinan phases reveals aspects of Islamic developmental methodology through the recognition of significant patterns and dynamics which not only underline the centrality of iman but interestingly lead to implications regarding hierarchical and sequential precedence when considering implementation of development methodologies.

Relating this sequential nature of Islamic development methodology to fig. 1 and superimposing the various spheres of iman and its actualisation it can be noted that the individual aspect, which may be termed the vertical element of iman, is the element which, through cognitive beliefs of the ultimate virtue, creates the trust pool. Furthermore the actualisation of iman, which may be termed its horizontal element, contributes to social capital and the forming of Islamic institutions. Thirdly there is a feedback effect whereby one intended effect of institutions is to facilitate and bolster the level of iman in society and hence expand the trust pool.

The holistic, or macro level perspective provides an understanding of the complex dynamic nature of the Islamic development methodology in so far as it reveals the interdependent, concurrent and continuous nature of the relationship of iman with institutions, of the individual with society and of trust with development. The implications of this include the fact that only when both phases of development, iman and institutions, function efficiently and concurrently will Islamic development be achieved and furthermore that such development is defined not by reaching any particular level or goal but by continuously moving towards the goal of Ihsan. Hence Islamic development is to be measured by how efficiently and extensively individuals and society are together moving through the Islam-iman-Ihsan journey and conversely failure may be measured by how extensively the barriers to such movement exist within the society.

\section{Reference}

Coleman, J. S. (1988). Social capital in the creation of human capital. American Journal of Sociology, 94.

Dasgupta, P. (1988). Trust as a commodity. In D.Gambetta (Ed.), Trust: Making and Breaking Cooperative Relations (pp. 49-72). Oxford: Basil Blackwell. 
Dunn, J. (1988). Trust and political agency. In D.Gambetta (Ed.), Trust: Making and Breaking Cooperative Relations (pp. 73-93). Oxford: Basil Blackwell.

Gambetta, D. (1988). Trust: making and breaking cooperative relations. Oxford: Basil Blackwell.

Granovetter, M. S. (1985). Economic action and social structure: the problem of embeddedness.

Granovetter, M. S. \& Swedberg, R. (1992). The sociology of economic life. Boulder, Colo; Oxford: Westview.

Hart, K. (1988). Kinship contract and trust: the economic organization of migrants in an African city slum. In D. Gambetta (Ed.), Trust: Making and Breaking Cooperative Relations ( Oxford: Basil Blackwell.

Luhmann, N. (1979). Trust and power: two works. Chichester: Wiley.

Putnam, R. D., Leonardi, R., \& Nanetti, R. (1993). Making democracy work: civic traditions in modern Italy. Princeton, N. J: Princeton University Press.

Shapiro, S. (1987). The social control of impersonal trust. American Journal of Sociology, 93, 623-658.

Swedberg, R. (1987). Economic sociology: past and present. Current Sociology, 35, 1-221.

Sztompka, P. (1995). Trust: the missing resource of post-communist society. Krakow: Institute of Sociology, Jagiellonian University.

Williams, B. (1988). Formal structures and social reality. In D. Gambetta (Ed.), Trust: Making and Breaking Cooperative Relations (pp. 3-13). Oxford: Basil Blackwell.

Williamson, O. E. (1985). The economic institutions of capitalism: firms, markets, relational contracting. New York: Free Press.

Williamson, O. E. (1993). Calculativeness, trust and economic organization. Journal of Law and Economics, 36, 519-540. 